\title{
Multilateral Nuclear Approach to Nuclear Fuel Cycles
}

\author{
Yusuke Kuno \\ Additional information is available at the end of the chapter \\ http://dx.doi.org/10.5772/53178
}

\section{Introduction}

The Fukushima Daiichi Nuclear Power Plant (Fu-NPP) accident, which occurred in March 2011, has significantly influenced the recent trend in the growing interest in nuclear reactor deployment. On the other hand, it is common knowledge that there remain problems in global climate changes and energy security in the long term view that human-beings are obliged to solve. Meanwhile, the issue on treatment of spent fuels (SFs) has become remarkably recognized. These facts should result in the continuous needs of nuclear energy and proper management of SFs, i.e., well-organized nuclear fuel cycle (NFC) services, including uranium mining, refining, conversion, enrichment, reconversion, fuel fabrication, spent fuel treatment such as storage, reprocessing, and repository.

The concerns for the nuclear proliferation of so-called "Sensitive Nuclear Technologies (SNTs)", and weapon-use nuclear materials, namely, enrichment technology (frontend), spent fuel reprocessing technology (backend) and fissile materials will increase. The latter includes concern with worldwide increase in the amount of SFs, which may have to be stored in individual states. Namely, there will be growing concerns from the nuclear non-proliferation and security perspectives that plutonium may globally proliferate as a form of SFs.

Measures for nuclear non-proliferation have so far been taken mainly by the combination of institutional systems and supply side approaches (see Fig.1). International society has been responding to the above-mentioned concerns by strengthening schematic measures centered around the safeguards under the NPT and Convention on the Physical Protection of Nuclear Material, etc. Bilateral agreements represent the latter one (supply side approach) particularly those between the US and individual states that have been functioning strongly. However, increase in the supply of fuel source materials from the Eastern Block has been remarkable in recent years, as shown in Fig.2, which may potentially weaken the influence of the Western Block on nuclear non-proliferation. 
The measures for enhancement of nuclear non-proliferation on the supply side that mainly consist of the nuclear power technology advanced countries may interfere with the inalienable right of peaceful uses of nuclear power that is guaranteed by Article 4 of the NPT. Thus, there is a need to develop nuclear non-proliferation measures with high non-proliferation capacity based on new concepts which are completely different from the conventional ones. In addition, as for the nuclear security for handling SNTs and nuclear materials as well as safety management of nuclear facility operations, the conventional state-by-state efforts have limitations from the viewpoints of effectiveness, efficiency, and economic reasonability.

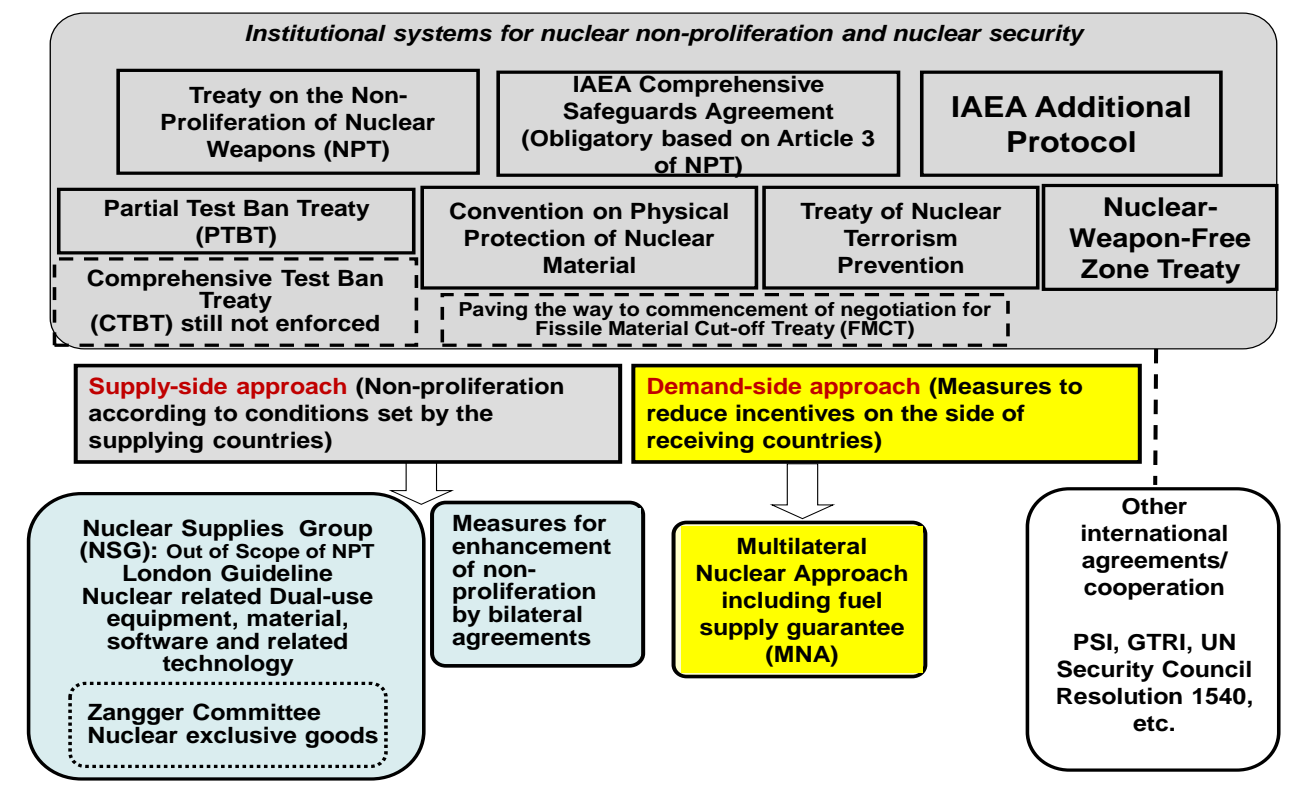

Figure 1. International Effort for Nudear Non-proliferation

Demand side approach represented by Multilateral Nuclear Approach (MNA), where services on the frontend and the backend are provided to the states possessing nuclear power plants without interfering with the inalienable right in NPT and measures for nuclear nonproliferation properly function, may be one of the most effective and efficient goals to solve all the problems discussed above. Originally the MNA was proposed as an idea to reduce the possibility of nuclear proliferation of sensitive technologies by supplying enrichment and reprocessing services to newcomer countries [1].

Regional MNA, e.g., in Asian regions, may also complement or reinforce the weakened nonproliferation regime of Western Block-based regions. 


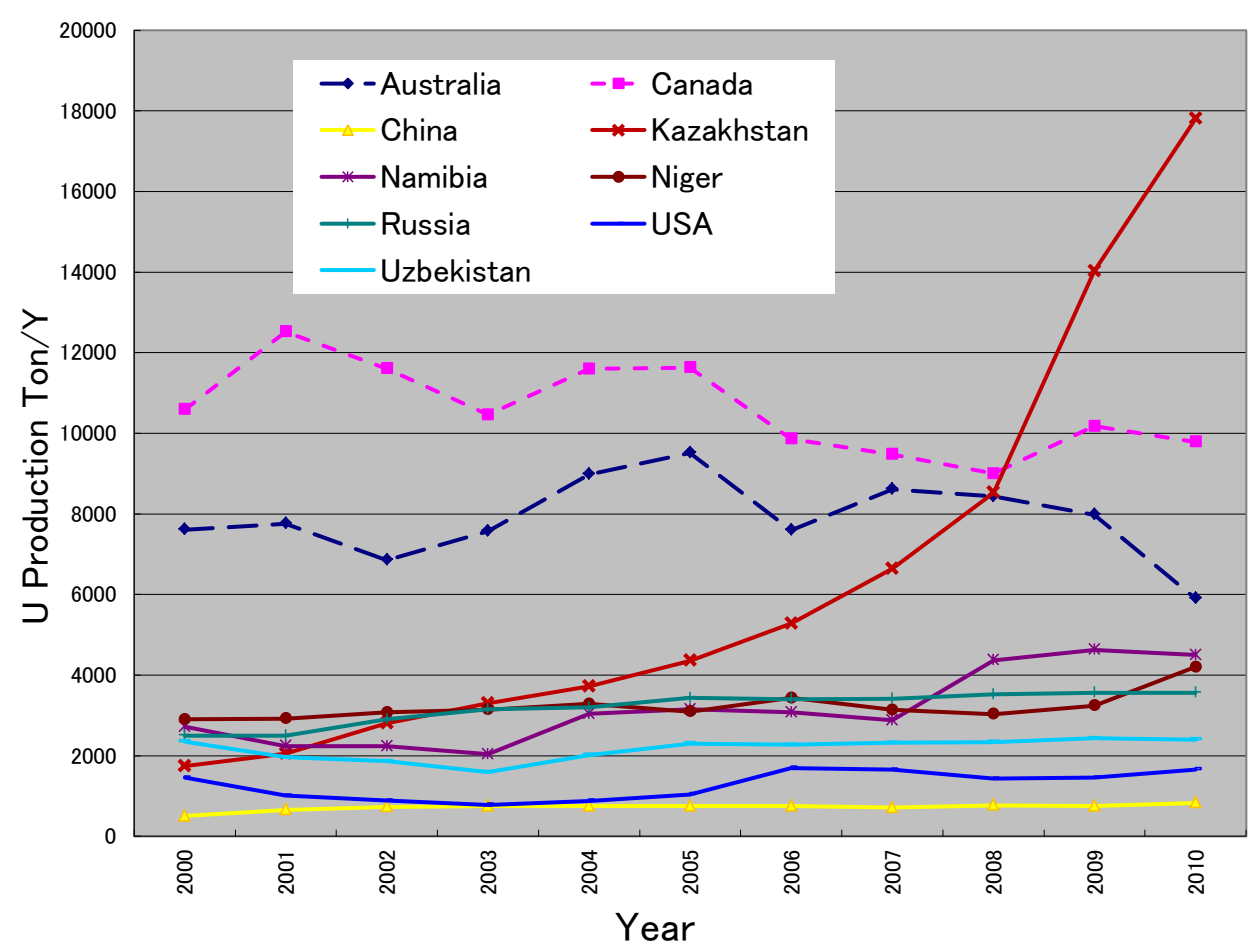

Figure 2. Diversification of Uranium Resource Supply. Data source: http:/www.world-nuclear.org/info/uprod.html

In the foreseeable future, most of newcomer countries utilizing nuclear energy would like to have a reliable system of fresh fuel supply and spent fuel treatment services, free of any political disruptions to fuel their nuclear reactors.

Several proposals [2,3] on the Multilateral Nuclear Approach (MNA) have recently been studied and a few are now ready to be implemented, in which no restraint of the peaceful use of nuclear energy due to the issues of proliferation of sensitive technologies is taken into account. Recent discussions, however, tend to focus on reliable fuel supply, namely frontend of NFC, where proliferation of uranium enrichment can be deterred. At the same time, the MNA capability to provide assurance/service that the SFs be managed properly is actually more important [4].

Storing SFs as well as possessing those in power reactors in individual countries remains problematic not only for Safety but also the risks in nuclear proliferation/Safeguards and Security (3S), due to the presence of large amounts of imbedded plutonium (Pu). Although $\mathrm{Pu}$ in SFs is protected by its high radiation dose rate, the technology to separate the plutonium from SFs (reprocessing) is not as difficult as uranium enrichment technology. It is therefore important to address the issues associated with the backend of the nuclear fuel cycle and to 
propose to properly manage/treat SFs. In this context, MNA may also be beneficial from the viewpoints of $3 \mathrm{~S}$.

\section{Historical review of international framework discussions - Past and recent proposals concerning MNA}

\subsection{Historical review of international framework [5]}

From the perspective of preventing proliferation of SNTs, the concept of "international control" has been proposed for a long time.

The old one is the international control of nuclear materials, which was developed under the Truman Administration in 1946 (i.e. pooling all nuclear materials, etc. in an international organization and lending them to states that want them). In January 1946, the United Nations Atomic Energy Commission (UNAEC) was founded based on the proposal by the US, the UK and Canada in November 1945 [6] that asked the international control of atomic energy, i.e., "control of atomic energy to the extent necessary to ensure its use only for peaceful purposes" and "elimination from national armaments of atomic weapons and of all other major weapons adaptable to mass destruction". In this way, MNA has been encouraged in line with the use of nuclear energy.

In the US, "A Report on the International Control of Atomic Energy" (also known as the "Acheson-Lilienthal Report") was prepared for discussion in the UNAEC. Based on the Declaration on the Atomic Bomb, the Report proposed to establish a new international organization called the "Atomic Development Authority (ADA)" which owns all fissionable material and controls them under effective leasing arrangements [7]. The report also proposed that the ADA would be in charge of all "dangerous" activities relating to raw materials, construction and operation of production plants, and the conducting of research into explosives, while "non-dangerous" nuclear activities, such as the construction and operation of power-producing piles, "would be left in national hands". It is interesting to note that in the report, all nuclear fuel cycle activities, except nuclear reactors, were categorized as "dangerous activities" and should not be conducted by an individual state.

In 1946, Bernard Baruch, the US representative to the UNAEC, submitted his plan for the international control of nuclear energy based on the Acheson-Lilienthal Report [8]. However, he modified the report by inserting the prohibition of the development of nuclear-weapons capability by new states and punishment for violations of such prohibition. The plan was not accepted by the Soviet Union and as a result, the international control of nuclear energy did not bear fruit in the 1940s.

This plan was later put on the table of the UNAEC in the form of "Baruch Plan" by UN Representative B. Baruch. However, the Plan did not take off successfully because it was contradicting with the US's free enterprise system of that time as it was promoting international ownership of the US technology. It also reached a deadlock in the negotiations 
between the US and the Soviet Union. However, the Plan triggered the "Age of International Collaboration for Peaceful Use of Nuclear Energy" in the "Atoms for Peace" speech by US President Eisenhower in 1953 at the UN. In this initiative, the uranium bank (reserve) with an intension of international management of fissile materials was proposed. After these debates, the International Atomic Energy Agency (IAEA) was established in 1957. Provision of nuclear materials, etc. became one of the missions of the IAEA. However, the uranium bank plan was eventually abandoned because a) uranium supply was not as limited as was initially envisioned, and b) competition of commercial nuclear energy technology/supply of nuclear materials in the major supplying states based on the above speech was intensified.

In post-war Europe, the European Atomic Energy Community (EURATOM) was established to promote nuclear energy development. The most important requirement of the EURATOM Convention was "to guarantee nuclear materials supply" by the member states [2]. At the same time, the Convention had safeguard systems to ensure that the nuclear materials within EURATOM were to be used only for peaceful uses.

International debate with regards to exporting nuclear technology and material/equipment promoted another international framework concerning the supply. In 1971, the Zangger Committee was established. The member states shall apply the IAEA's safeguards to the exported "nuclear materials" when exporting them to the non-NPT member states without nuclear weapons as well as when transporting them from these nonnuclear weapons states. The Committee also created a list of equipment as subjects of the regulation. Meanwhile, after the first nuclear test by India, the Nuclear Suppliers Group (NSG) was established in 1974 for a similar purpose. The NSG controls exports based on the so-called "NSG Guidelines", the guidelines designed for the states which export nuclear energy related equipment, material and technologies (it is a "gentleman's agreement" without any legal binding power).

In 1975, the IAEA began the exploration of the first Regional Nuclear Fuel Cycle Center (RFCC) [9] and assessed the advantages of applying backend to the RFCC. The RFCC report examined and presented basic research from international and regional approaches regarding the backend of fuel cycle in various geographical sites. From 1977 to 1980, the International Nuclear Fuel Cycle Evaluation (INFCE) [10] was conducted, and the effectiveness of nuclear fuel cycle was thoroughly evaluated by 8 working groups (WGs). Through this activity, many WGs picked up "fuel cycle center" and described it as a systematic arrangement to strengthen nuclear non-proliferation. Furthermore, for the spent fuel issues, they considered the fuel cycle as a solution that includes legal framework and multinational arrangement. Based on the results of the INFCE, the IAEA supported the experts group to examine the concept of international plutonium storage (IPS) [9], established the Committee for Assurance of Supply (CAS) [9] in 1980 and continued the deliberation until 1987. The experts' examination concluded that the multilateral approach was technically and economically feasible but there were still issues in terms of difficulty in 
prerequisites for participation and transfer of rights towards nuclear non-proliferation. Most of those activities, initiated by the US-initiatives, could not agree on the non-proliferation commitments and conditions that would entitle states to participate in the multilateral activities" [11], because nuclear developed states in Western Europe and Japan had already engaged in the development of their own sensitive capabilities. Therefore, they tried to maintain their activities, and not let them be interfered with by such initiatives. Developing states, especially NAM states, argued that any requirements for the non-proliferation commitment of not engaging in sensitive nuclear activities were against Article IV of the NPT. They also insisted such a requirement would discriminate between the "haves" and "have-nots" of sensitive capabilities, in addition to there being an existing discrimination by the NPT between "NWS" and "NNWS". The US was thus left alone and could not gain enough support for promoting its initiatives any further. Together with Cold War tensions, a decline in the growth rate of the US economy and a decrease of energy demand due to the second oil shock in 1979, and discouragement of nuclear energy use after TMI and the Chernobyl accidents in 1979 and 1986, the US itself lost its motivation for MNA.

At GLOBAL 93, an international conference, the "International Monitored Retrievable Storage System (IMRSS)" [12] was proposed by Dr. Häfele from Germany. IMRSS proposed that spent fuel and plutonium shall be stored in a retrievable condition under monitoring by an international entity. It chose the IAEA as a desirable entity to lead the initiative. Although it was considered a temporally measure to buy some time until the conclusion of whether SFs would be directly disposed or plutonium would be retrieved, there was no development thereafter. Dr. A. Suzuki of the University of Tokyo made a proposal for spent fuel storage in the East Asia region, and Dr. J-S. Choi of CISAC/Stanford University made a proposal for the regional treaty including regional spent fuel storage. Their proposals show the significance of the systems in which the host states offer interim storage of SFs for a limited time (40 to 50 years), even though the handling of SFs from other states is not easy.

In 1994, the US and Russia agreed that the US would purchase 500 tons of highly-enriched uranium (HEU) from Russia, convert it to low-enriched uranium (LEU) and make peaceful uses of it. Furthermore, both states agreed that each state would declare 50 tons of excess plutonium to be used for defense purposes, dismantle and retrieve 34 tons from nuclear weapons, and convert it to power generating fuel as MOX. For the purpose of nuclear non-proliferation, the US also began the "Foreign Research Reactor Spent Nuclear Fuel Acceptance Program (FRRSNFA)" in 1996 to accept the US-origin spent HEU and LEU fuels from foreign research reactors by May 2009. Furthermore, under the Russian Research Reactor Fuel Return (RRRFR) Program, some 2 tons of HEU and some 2.5 tons of LEU SFs, which were previously supplied by Soviet Union/Russia to foreign reactors, were shipped to the Mayak reprocessing complex near Chelyabinsk. The US and the Russian Federation cooperated in several repatriation projects for Russian-origin HEU fuels. 
Based on the recognition that SFs and high level waste (HLW) are the common critical issues which could be factors to hinder nuclear energy promotion in the East Asia region, the Pacific Nuclear Council (PNC) began deliberation to promote understanding and cooperation for the management of SFs and HLW among the PNC members and to investigate possibilities of the International Interim Storage Scheme (IISS) in 1997. The IISS is managed at national, regional, or international levels and is to augment (not to replace) the national system. The IISS operates during the contract period from the time when SFs and HLW are deposited to the storage facility in the host state till the time when "they are returned to the originating state". The host state would be responsible for safety and safeguards of the storage facility and receive financial compensation from the contact member state, which is the owner of the SFs and HLW.

In reality, the interim storage of SFs, a part of a reprocessing contract, had been offered by reprocessing operators such as the BNFL and the AREVA. With this system, the state which makes a reprocessing contract can store SFs as long as it is stored in the reprocessing facility; however the separated plutonium and HLW at the time of reprocessing would be returned to the state. On the other hand, the concepts of the IMRSS, the RSSFEA, regional treaty and the IISS demand the host state to store or dispose of other state's SF. However, this is not easy in reality.

\subsection{Recent proposalsp $[13,14]$}

The concerns about nuclear proliferation by states and the acquisition of nuclear weapons by terrorists has grown after nuclear testing by India/Pakistan in 1998 and the terrorist attack on September 11, 2001. The nuclear weapons black market network issues by Democratic People's Republic of Korea (DPRK, hereafter referred to as North Korea), Libya, Iran and A.Q. Khan are driving the international society to make efforts through various trials and proposals in preventing proliferation of the SNT related to fuel cycle such as isotope separation and reprocessing.

The proposals made by Ex-Director General of the IAEA, Dr. M. ElBaradei, in October 2003 presented that (1) reprocessing and enrichment operations must be restricted under the multinational control, (2) nuclear energy system shall have nuclear non-proliferation resistance, and (3) multinational approaches shall be considered for the management and disposal of SFs and radioactive waste. However, it was anticipated that his idea of a multilateral system of SNTs and radioactive substances would take a long time to overcome the issues.

Former US President G.W. Bush strongly demanded in his speech at the Defense University in February 2004 that exporting SNTs should be limited to the states which were already using them on a full scale and respecting the Additional Protocol. However, this proposal may lead to international cartels and may split the member states into the states with SNTs and without SNTs. The "Nuclear Fuel Leasing" proposal by V. Rice, et al. and "Nuclear Fuel Service Assurance Initiative" proposal by E. Moniz, et al. expect the improvement of nuclear non-proliferation though institutionalization. However, the proposals still contain a concern over supply assurance to the user states as well as a concern over the dichotomization of the member states, similar to the other proposals. 
Later, a group of experts for multinational nuclear (fuel cycle) approaches (MNA) was formed (ElBaradei Commission). The group was assigned to (1) identify and provide an analysis of issues and options relevant to multilateral approaches to the frontend and backend of the nuclear fuel cycle, (2) provide an overview of policy, legal, security, economic, institutional and technological incentives and disincentives for cooperation in multinational arrangements, and (3) provide a brief review of the historical and current experiences and analysis relating to multinational fuel cycle arrangements. In the report, MNA was assessed based on two primary factors, namely, assurance of supply and services, and assurance of nuclear non-proliferation. Furthermore, 3 potential MNA options were presented.

i. To strengthen existing market mechanisms case by case with assistance from governments through long-term and transparent arrangement;

ii. To establish an international supply assurance such as fuel bank in collaboration with the IAEA as an organization to assure fuel supply; and

iii. To promote voluntary transformation of existing facilities of member states to MNA (including regional MNA by collaborative ownership and collaborative administration)

The study results by the expert group at the IAEA are summarized in INFCIRC/640, which give an impact on the successive examination of multinational approach framework. After this report, a number of proposals related to supply assurance and multilateral approaches were put forward. The following are some of these proposals/approaches [15]:

1. In order to achieve "Reliable Fuel Supply (RFS) Initiative", announced by former Secretary of the US Department of Energy (DOE), Bodman in September 2005, the US is in the process of down-blending about 17.4 tons of HEU to about 290 tons of LEU (4.9\%) within 3 years and storing them. The RFS Initiative was later renamed to the American Assured Fuel Supply (AFS) and it will be operational in 2012.

2. During the discussion of fuel supply assurance at the Global Nuclear Energy Partnership (GNEP), the US, in collaboration with the partner states, declared that it would aim at establishing a fuel service mechanism including fuel supply at frontend and SF disposal at backend to achieve international nuclear non-proliferation. In the Nonproliferation Impact Assessment (NPIA) presented by DOE in January 2009, the importance of maintaining advanced reprocessing capacity including minor actinide recycling was insisted. It also emphasized the significance of the US's participation in the overall fuel services including backend service in order to suppress incentives for the emerging states to individually develop enrichment and reprocessing technologies. Later, being influenced by political regime change, the GNEP terminated its domestic activities (i.e. cancellation of prompt construction of commercial reprocessing facility and fast reactor) and decided that they would maintain international collaboration framework as International Framework for Nuclear Energy Cooperation (IFNEC) only for international activities from 2010. The fuel supply working group at IFNEC expressed its willingness to support collaborative actions among member 
states and organizations towards establishment of an international fuel supply framework. It would also provide trustworthy and worth-the-cost fuel services/supply to the global market and provide options relating to the development of nuclear energy usage in accordance with reductions of nuclear proliferation risks. The new director expressed his speech its willingness to achieve so-called "from cradle to graveyard".

3. World Nuclear Association (WNA) proposed a three-level assurance mechanism: 1) basic supply assurance provided by the existing market, 2) collective guarantees by enrichment operators supported by relevant governmental and the IAEA commitments, and 3) government stocks of enriched uranium product. According to them, it is necessary to promote the idea of an international reprocessing recycling center when nuclear energy usage is expanded in the future.

4. Reliable Access to Nuclear Fuel (RANF) (nuclear fuel supply assurance concept by 6 states): Similar to the above, this proposal contains a three-level mechanism: 1) supply through market, 2) system in which enrichment operators would substitute for each other based on the collaboration with the IAEA, and 3) virtual or physical low-enriched uranium banks by a state or the IAEA.

5. Japanese proposal: The states willing to participate shall voluntarily register at/notify the IAEA of their capacities (current stockpiles and supply capacity), and the member states shall notify the IAEA of their service provision capacity in accordance with the availability of service utilization capability by three levels (Level 1: provision of service on the domestic commercial basis - no exporting on a commercial scale, Level 2: international provision on a commercial basis, Level 3: storage that can be exported for a short time). The IAEA would make an agreement of standby-arrangement with member states and manage the system. If the fuel supply actually gets confused in a state, IAEA will play a role as a mediator. This proposal is to improve market transparency, prevent supply termination, and augment the RANF proposal.

6. UK Enrichment Bond proposal: Enrichment tasks shall be carried out by domestic enrichment operators. The supplying state, the consuming state and the IAEA will make a treaty in advance. The IAEA shall approve commitment of the consuming state for nuclear non-proliferation. If assurance is activated by bonding, the supplying state would not be prevented from supplying enrichment services to a consuming state. This proposal is to enhance credibility of supply assurance mechanisms and augment the RANF proposal. The Bond proposal was later renamed the Nuclear Fuel Assurance (NAF) proposal and was approved by the IAEA Board of Governors in March, 2011.

7. The Nuclear Threat Initiative (NTI) proposal [16]: This is a storage system for LEU stockpiles possessed and controlled by the IAEA, and it is the anchor proposal for actual realization. For the activity of the NTI, the US pledged $\$ 50$ million, Norway $\$ 5$ million, the United Arab Emirates \$10 million, the EU \$32 million, and Kuwait offered \$10 million. The total pledge has reached $\$ 107$ million. Furthermore, in April 2009, Kazakhstan's President Nazarbayev announced that the country was ready to receive the IAEA nuclear fuel bank and officially announced its willingness to be a host state in January 
2010 (INFCIRC/782). In May 2009, the IAEA presented a proposal for deliberation at the Board of Governors meeting held in June 2009. The proposal included consuming state's requirements in relation to the IAEA nuclear fuel bank, supply processes, contents of model agreement (e.g. supply price of LEU, safeguards, nuclear material protection, nuclear liability), etc. Later, at a regular Board of Governors meeting on December 3, 2010, the establishment of "nuclear fuel bank" which will internationally manage and supply LEU to be used as fuel for nuclear energy generation was agreed on. If the IAEA receives a request from a state which cannot purchase LEU due to exceptional circumstances impacting availability and/or transfer and is unable to secure LEU from the commercial market, state-to-state arrangements, or by any other such means, the IAEA will supply LEU to the state at the market price under the guidance of the Director General of IAEA. Through this agreement, the first system in which LEU would be controlled by an international organization began. The IAEA owns the bank based on the contributions from the member states. The Board of Directors will later deliberate the location of the bank. Kazakhstan is already declaring its candidacy to be a host state. The resolution was proposed collaboratively by over 10 states including the US, Japan and Russia and was adopted with 28 states voting in favor. The developing countries which were planning to have nuclear energy later had been insisting that the bank would lead to a monopoly of nuclear technology by developed countries and "right for peaceful use of nuclear energy" stipulated by the NPT would be threatened. To address this issue, the resolution clearly stated that it would not "ask for abandoning" nuclear technology development by each state and obtained understanding from the developing countries.

8. International Uranium Enrichment Center (IUEC) [17]: The IUEC was established in Angarsk, Russia, with investment by Russia and Kazakhstan. The IUEC is not only to assure supply but to provide uranium enrichment services. Thus, this proposal is more realistic than the others. The proposal states that the uranium enrichment technology will be black-boxed, namely, the investing states will not be informed, and the technology will be under the control of the IAEA. Other than Russia and Kazakhstan, Armenia and Ukraine are now members of the IUEC, while Uzbekistan is expressing its intention of participation. It will have the LEU reserve of two 1000MWlevel cores. In May 2009, for the deliberation at the IAEA Board of Governors meeting held in June, Russia submitted the proposal including the summary of agreement for LEU storage between the IAEA and Russia and summary of agreement for the LEU supply between the IAEA and the consuming states. In November 2009, being led by Russia, the nuclear advanced states submitted a resolution to the IAEA Board of Governors in November. The resolution was to seek approval of two agreement plans: 1) agreement plan between the IAEA and Russia to establish the LEU reserve under Russian IUEC, and 2) a model agreement plan between the IAEA and the LEU recipient states concerning the LEU supply from the reserve. The resolution was approved by a majority. In March 2010, the IAEA's Director General, Amano, and Director General of Rosatom Nuclear Energy State Corporation, Kiriyenco, sign- 
ed on the agreement for the establishment of the LEU reserve under Russian IUEC, and the LEU storage was established in December, 2010.

9. Multinational Enrichment Sanctuary Project (MESP) (proposed by Germany): This proposal is for the IAEA to manage enrichment plants and exportation on an extra-territorial basis in a host state. The SNT will be black-boxed.

10. The Science Academies of the US and Russia presented analysis and proposals for nuclear fuel assurance as a measure to prevent proliferation of nuclear weapons under the title of "Internationalization of Nuclear Fuel Cycle - Goals, Strategies, and Challenges"13. In its report, the options and technological issues for the future international nuclear fuel cycle are presented. The report also contains the analysis of the incentives for the states that opt for accepting fuel supply assurance and developing enrichment or reprocessing facilities and do not opt for it. Furthermore, they examined new technologies for reprocessing/recycling and new reactors and made various proposals to the governments of the US and Russia and other nuclear supplier states to stop proliferation of SNTs and contribute to reduction in the risk of nuclear weapons proliferation. The report analyzed and summarized critical issues and presented several standards for assessing the options.

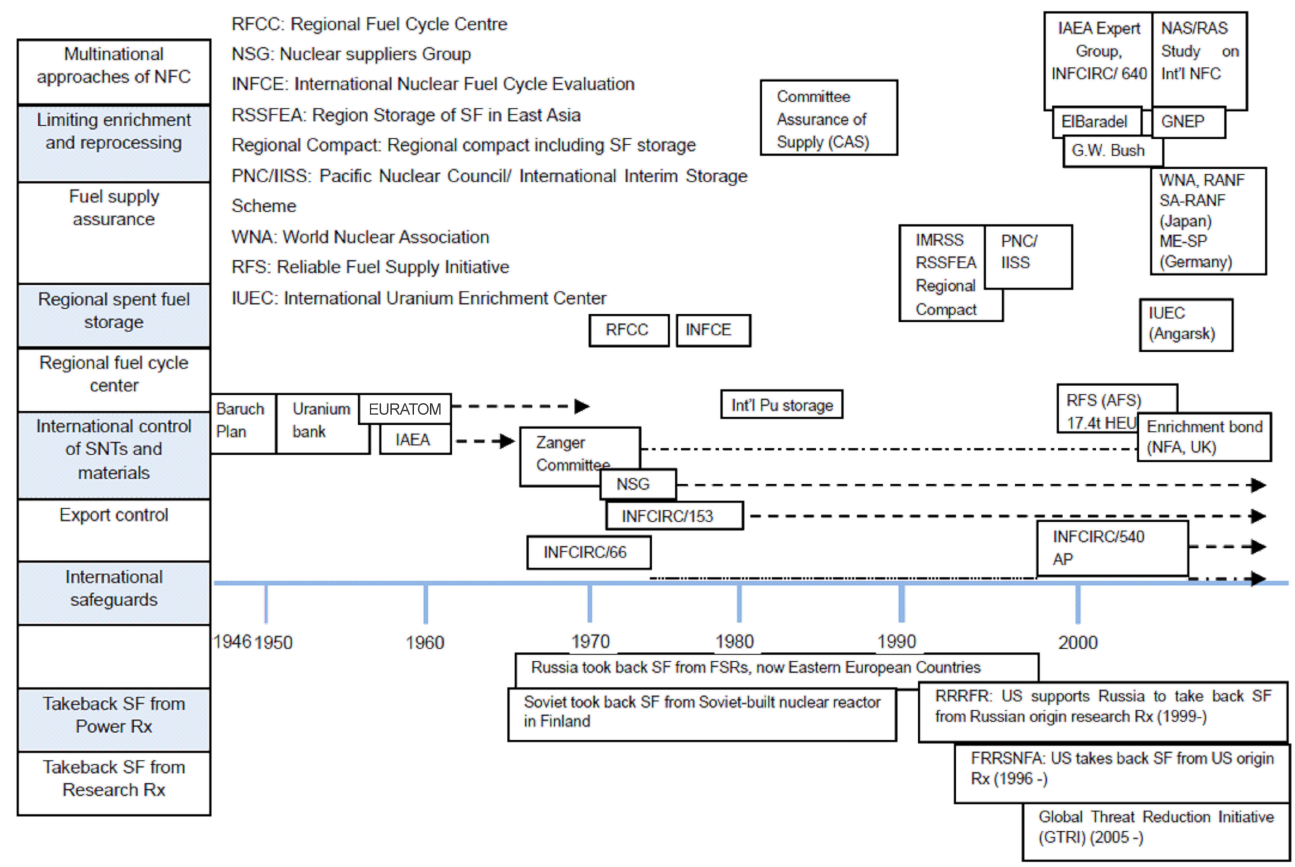

Figure 3. Transition of Proposals/Initiatives for International/Regional Management of Nuclear Fuel Cycle Relevant to Nuclear Non-proliferation 
Figure 3. summarizes the flow of nuclear non-proliferation measures centered on multilateral approach/supply assurance in the past. As shown, the debates have become more and more active in recent years, and the need for internationalization of fuel cycle, which was not very realistic until now, is gradually becoming a reality. As described above, as of December 2011, the IAEA nuclear fuel bank, LEU reserve in Angarsk, Russia, and the UK's NFA proposal were approved by the IAEA Board of Governors, and the US's AFS begin its operation in 2012.

\subsection{Issues with the past and current proposals}

Most of the past proposed MNAs had never been implemented in any form until the nuclear fuel bank 7) and the LEU-IUEC storage 8) were approved by the IAEA Board of Governors. It was probably because nuclear proliferation was not recognized as a sufficiently serious issue and there was not a very strong economic motivation. Many proposals included unfair double standards, i.e., "have" and "have not", and inconsistency with Market Mechanism. Also need of MNA may not have matured, or become critical yet.

However, as explained above, the situation has been changing in the last few years. Despite the Fukushima Nuclear Power Plant accident as well as the actual global concern over nuclear non-proliferation, the expansion of peaceful uses of nuclear energy in the world is unavoidable in the a long term. In that sense, the role of supply assurance was reviewed, and some of the above mentioned proposals have been approved by the IAEA Board of Governors.

\section{Significance of MNA}

Significance of NMA, namely, MNA's benefits and incentives of individual stakeholders may be summarized as follows:

New nuclear non-proliferation regimes based upon mutual confidence and transparency, including regional safeguards, can be established, which can strengthen the function of nuclear non-proliferation.

Formulation of no discriminatory framework can be the primary incentive to make states join MNA. Recent criteria-based approaches of export of sensitive technologies in NSG [18] would help create a framework taking into account NPT Article IV.

Nevertheless, the number of enrichment and reprocessing facilities can be limited from the viewpoints of their needs (capacities) and nuclear nonproliferation, although every participating country can formally have the right to possess such SNTs.

Services on spent nuclear fuels, take-back, take-away, storage, reprocessing etc, can systematically be assured. Recipient countries can enjoy such services in NMA framework.

It is also expected that the host country in MNA would be discouraged to divert nuclear materials and to misuse related technologies because of the multilateral control of the fuel cycle facilities. 
To minimize proliferation risks on SFs: accumulation of SFs, e.g., in power reactor user countries, has become serious issue in the world. By leaving such spent fuel in individual countries, there is also a certain level of risk to make such countries change the policy, i.e., to have an incentive to try reprocessing.

Improvement in $2 S$ (safety/security) can be expected if for NMA framework systems to deal with such issues within the framework can be included, e.g., application of international standards among the participating countries.

Host countries may be able to expand their nuclear fuel cycle business capabilities further although facilities are expected to be controlled under/by MNA.

\section{Prerequisites/features for establishing MNA}

INFCIRC/640 (Pellaud Report) [19] proposed 7 elements of assessment called "Label" as prerequisites/features. In INFCIEC/640a variety of different issues are included altogether and the importance of each issue, such as nuclear security and safety, and political and public acceptance, is not focused individually, even though these are contemporary topics particularly following the Fukushima nuclear accident. Therefore, the following 12 elements, namely with 5 additional Labels, can individually be described as a full set of prerequisites or features to be considered for the formulation of a new framework of MNA as discussed elsewhere [20].

Label a: Nuclear non-proliferation

This includes safeguards, nuclear security and export control. If a state meets certain criteria (e.g. regional safeguards under MNA, nuclear security, export control), it is considered that the state can adequately maintain nuclear non-proliferation resume. Thus, the possession of sensitive nuclear technologies (SNTs) (i.e. uranium enrichment and spent fuel reprocessing), which is one of the measures for nuclear non-proliferation, would not necessarily be limited (criteria-based approach).

Label b: Fuel cycle service

An appropriate state becomes a host state or siting state (that provides/lets site) and offers fuel cycle service, based on the above-mentioned criteria-based approach. It includes uranium fuel supply service and services on spent fuel treatment. The latter should be made with a clear plan/agreement for long-term spent fuel treatment (storage / recycling / direct disposal), e.g., reduction of nuclear waste toxicity (HLW to medium level), individual member states to receive final waste, and use of MOX, in order not to bring concern to host/siting states.

Label c : Selection of a host state (siting state)

The state that meets all the criteria can be a host state or siting state. The specific criteria to participate in the multinational framework or to be host/siting state are, for instance, to sat- 
isfy conditions almost equivalent to the "objective criteria" described in INFCIRC 254 part 1-6, 7 (NSG guideline revised) 18, that is, member states are in full compliance with its obligations under NPT/safeguards agreement, are adhering to the NSG Guidelines, apply agreed standards of physical protection and have committed to IAEA safety standards.

Label d : Access to technology

Particularly, the access to SNTs should be strictly controlled under the MNA Framework.

Label e : Multilateral involvement

This includes 1) having multilateral cooperative system on e.g., safeguards, safety, and security, and 2) provision of services with or without transfer of facility ownership to MNA.

Label f : Economics

MNA, as a whole, increases economy when compared with management by individual states.

Label g: Transport

Member states should cooperate and maintain international standards for nuclear material transportation beyond borders.

Label h : Safety

International safety standards should be met within MNA.

Label i : Liability

MNA should cover a certain level of liability.

Label j : Political and public acceptance

Individual host or siting states should obtain political and public acceptance in corporation with MNA.

Label k : Geopolitics

Practically it should be taken into account if the stat is geopolitically stable.

Label 1 ; Legal aspect

Table 1 summarizes the existing treaties and agreements that correspond to each Label to be considered for MNA.

The gap between the new-MNA and existing related laws and agreements, which may conflict in some cases, should be adjusted. In particular, new MNA framework must have equal or higher capability on nuclear non-proliferation (Label a), e.g., in order to adjust the existing bilateral agreement that may be one of the strongest measures among the existing nonproliferation systems. In other words, the MNA member states must basically assure conditions set forth in the international treaties and agreements. 


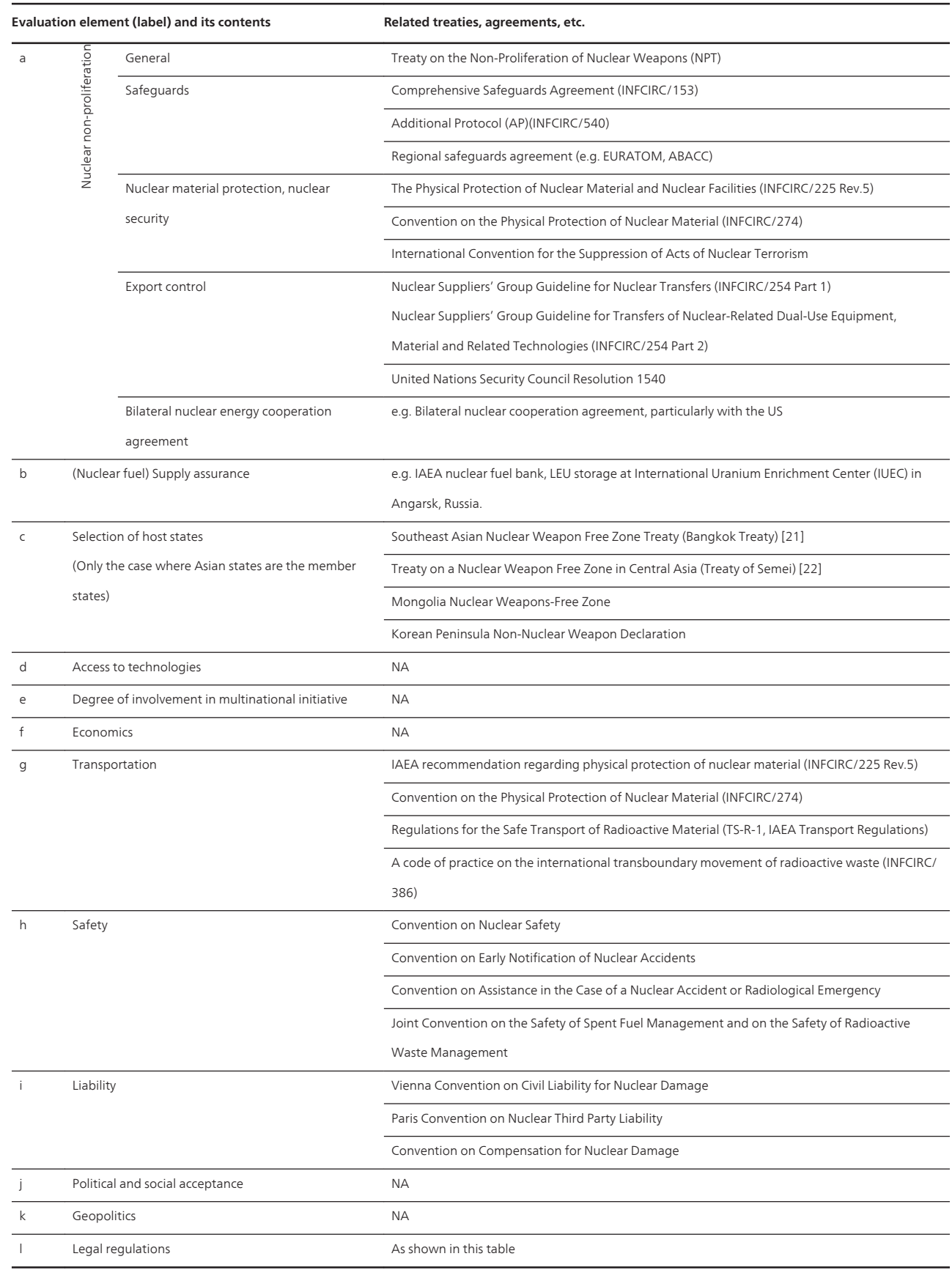

Table 1. Existing Treaties and Agreements to be Considered for MNA 


\section{An example of specific MNA framework study [21, 22, 23, 24, 25]}

The author's group has been studying an example of MNA framework, where strengthening of international non-proliferation scheme and provision of stable energy/nuclear fuel cycle services in a region are discussed. It contributes to enhancement of transparency and trustbuilding in the region. The study investigated the schematic issues and the countermeasures concerning the specific measures to achieve stable maintenance of the multilateral international nuclear fuel cycle including stable uranium supply system, spent fuel treatment system, usage of plutonium, establishment of regional safeguards scheme for the international nuclear fuel cycle, requirements for an organization that carries out international nuclear fuel cycle, and roles of industry in the international nuclear fuel cycle scheme. An image of framework scope is given in Fig.4. Outline of the study is shown below,

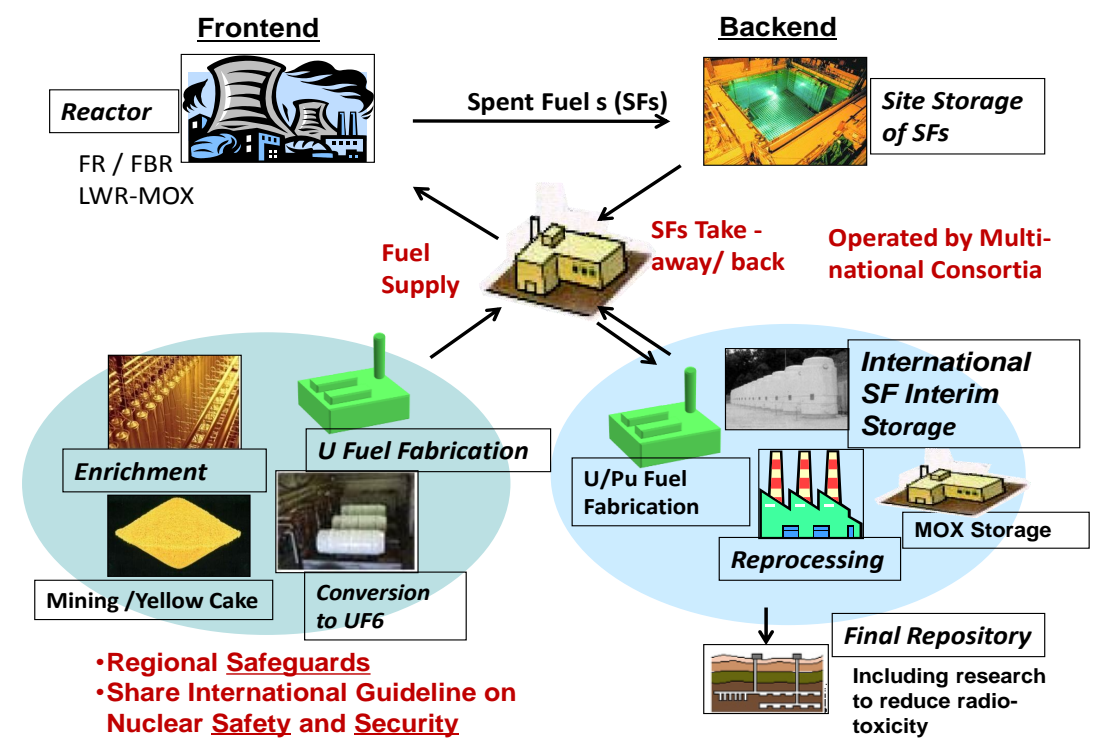

Figure 4. Possible framework of Future Nuclear Fuel Cycle

Three options on MNA system, Type A, B and C as shown below are defined.

Type A: No involvement of services (assured) of fuel supply, spent fuel storage and reprocessing, but regional framework for 3S.

Type B: Provision of services (assured) of fuel supply, SF storage and reprocessing without transfer of ownership of facilities; including regional framework for 3S.

Type C: Provision of services (assured) of fuel supply, spent fuel storage and reprocessing, MOX storage with ownership transfer of facilities to MNA; regional framework for 3S (with IAEA - arrangement). 


\section{(Specific framework proposed)}

It is targeted to the Asian region

It establishes MNA Operating Organization as the core of the framework function

Conclude Treaty on Regional NFC and related Agreements between States and the Organization.

In the multilateral framework, the system/facilities are divided into the Type A, Type B and Type C. Plutonium-handling facilities such as reprocessing, MOX fuel fabrication, Fast Reactors, and MOX storage facilities should be controlled under type $\mathrm{C}$, whereas uranium enrichment facility and spent fuel storage can probably be categorized as Type B or C depending on the siting countries. LWR MOX reactor would be Type A, while direct disposal should be Type $B$.

Regarding SFs, the MNA consisting of host, siting, and recipient states has clear plan for long-term spent fuel treatment, i.e., recycling / direct disposal, reduction of nuclear waste toxicity and use of MOX, within a specific certain period in order not to bring concern to host/siting states.

MNA develops technologies and services of reprocessing to reduce radio-toxicity of HLW (e.g., HLW to medium level) that would make an individual member receive final disposal waste easier.

It establishes Regional Material Accounting and Safeguards system within the MNA Framework to implement the nuclear non-proliferation regime, as described in Fig 5. The MNA agreement contains high level of nuclear non-proliferation capability, equivalent to the existing bilateral agreements (e.g. one with the United States).

The MNA has function to attain the international level on nuclear safety and security for facilities within the Framework (not only for fuel cycle facilities but also nuclear power reactors); criteria and inspection system.

The MNA has agreement with technology holders to precisely manage and control the SNTs (limited to technology-holding operators only).

Obligation with regards to nuclear non-proliferation is performed equally by the member states, while it is guaranteed that the right of peaceful uses of nuclear energy pursuant to Article 4 of NPT is not interfered with.

The specific requirement to participate in the multilateral framework is to satisfy conditions almost equivalent to the "objective criteria" described in INFCIRC 254 part 1, 6-7 (NSG Guidelines revised in 2011, see below ${ }^{*}$ ).

The MNA Framework is to be more economically advantageous than the fuel service on per state basis.

Framework member states cooperate on and agree to "transport" with regards to the nuclear fuel cycle service. 
Liability for compensation of damages at a possible level is agreed to within the Framework.

The member states cooperate in efforts to obtain public consensus in host and siting states. Any legal regulation to be inconsistent with, or antagonistic to, existing international rules, bilateral agreements, etc. is cleared.

Framework meets the recent Nuclear Industries' recognition on Safety, Health and Radiation Protection; Physical Security; Environmental Protection and Handling of Spent Fuel and Wastes; Compensation for Nuclear Damage; Nuclear Non-Proliferation and Safeguards; and Ethics, as described in "Principle of Conduct" for nuclear power plant exporters [26], where the plant manufactures (=Venders) should consider when exporting nuclear products.

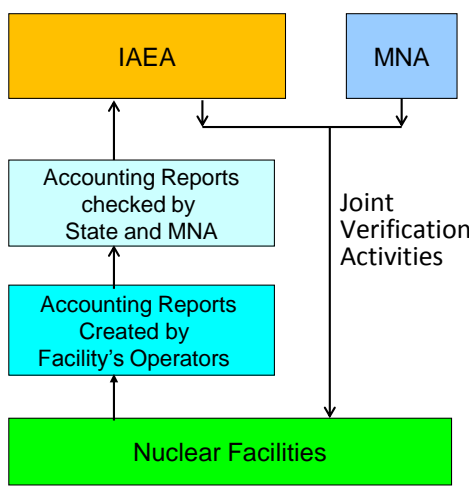

Type A \& B

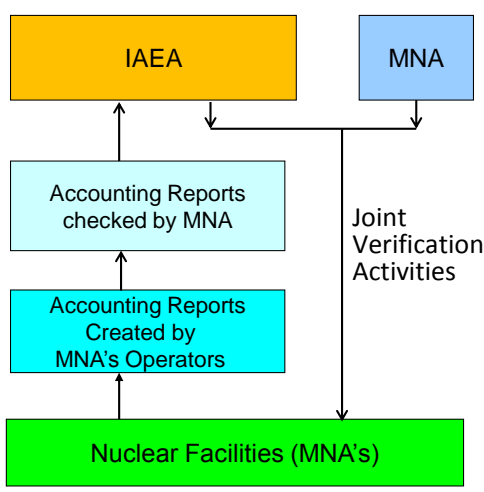

Type C

Figure 5. Regional Safeguard System

[NSG Guidelines* (INFCIRC/Rev.10/Part.1, 26 July 2011)[18]

NSG members would not authorize transfers of enrichment and reprocessing technology unless the intended recipient met certain "objective" criteria:

Be party to the NPT and in full compliance with the treaty,

Has not been identified in a report by the IAEA Secretariat which is under consideration by the IAEA Board of Governors, as being in breach of its obligations to comply with its safeguards agreement, nor continues to be the subject of Board of Governors decisions calling upon it to take additional steps to comply with its safeguards obligations or to build confidence in the peaceful nature of its nuclear program, nor has been reported by the IAEA, Is adhering to the NSG Guidelines and has reported to the Security Council of the United Nations that it is implementing effective export controls as identified by Security Council Resolution 1540,

Has concluded an inter-governmental agreement with the supplier including assurances regarding non-explosive use, effective safeguards in perpetuity, and retransfer,

Has made a commitment to the supplier to apply mutually agreed standards of physical protection based on current international guidelines, and

Has committed to IAEA safety standards and adheres to accepted international safety conventions. 
The outline of the management structure for the framework to meet the proposed concept is given in Fig. 6, where a basic treaty and many agreements on export, fuel supply, safety, security, safeguards, transfer of facility, SF services, sensitive technology control needs to be concluded among member states, and between state and AMNAO, technology holder and AMNAO, IAEA (and/or other international organization) and AMNAO. Also support of IAEA is essential for establishment of such international framework and system.

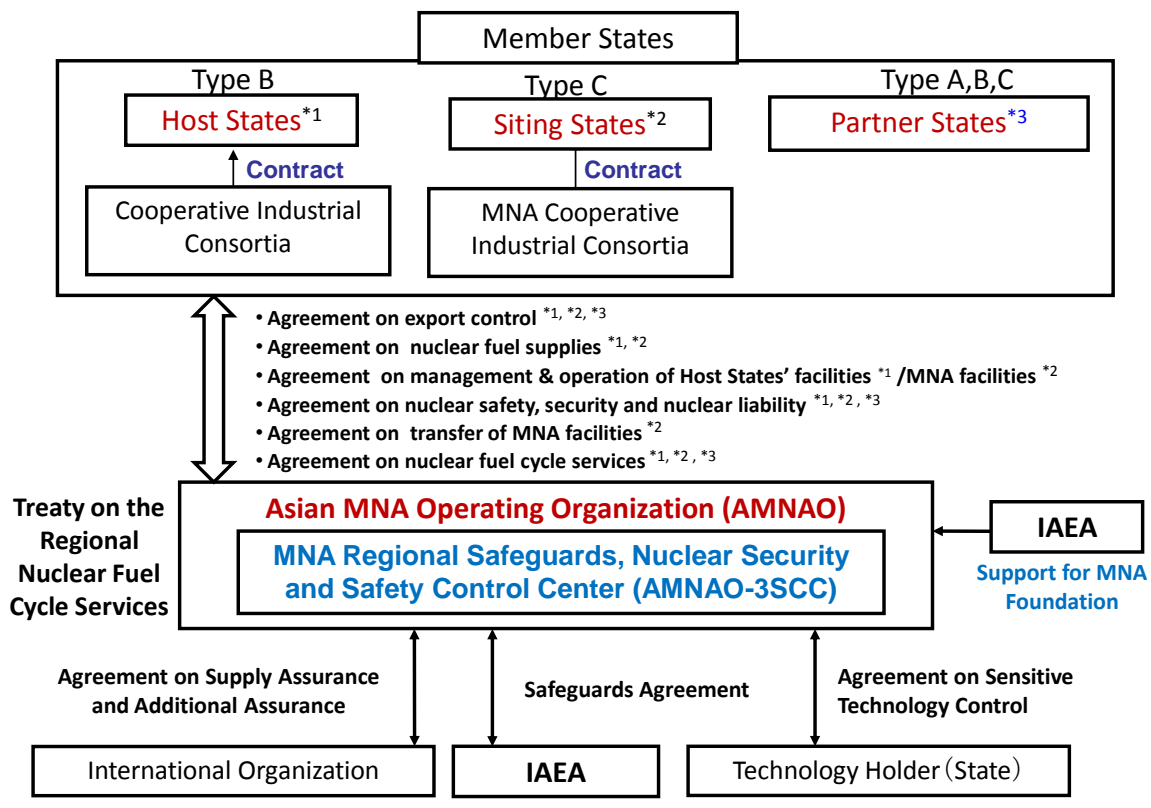

Figure 6. Treaty/Agreements Needed for the Foundation of MNA Model Structure

The treaty on the Regional Nuclear Fuel Cycle may consist of the following articles:

Preamble: Objective, Scope, Definition, Rights and Obligation, Signors

Article 1: Promotion of Foundation and Operation of Cooperative Industrial Consortia

Article 2: Limitation of commercial use, Obligation for Cooperative Industrial Consortia

Article 3: Industrial Rights Article 4: Sensitive Technology

Article 5: Safeguards Article 6: Resolution of Dispute

Article 7: Nuclear Security and safety Article 8: Withdrawal

Article 9: Licensing Article 10: Transport

Ending Part Protocol, Attached Documents 
An example of specific Asia region MNA cooperation is shown in Fig. 7, which may complement or even reinforce the present non-proliferation regime. At the same time, the new proposed scheme may enable the region to have international storage of SFs and MOX.

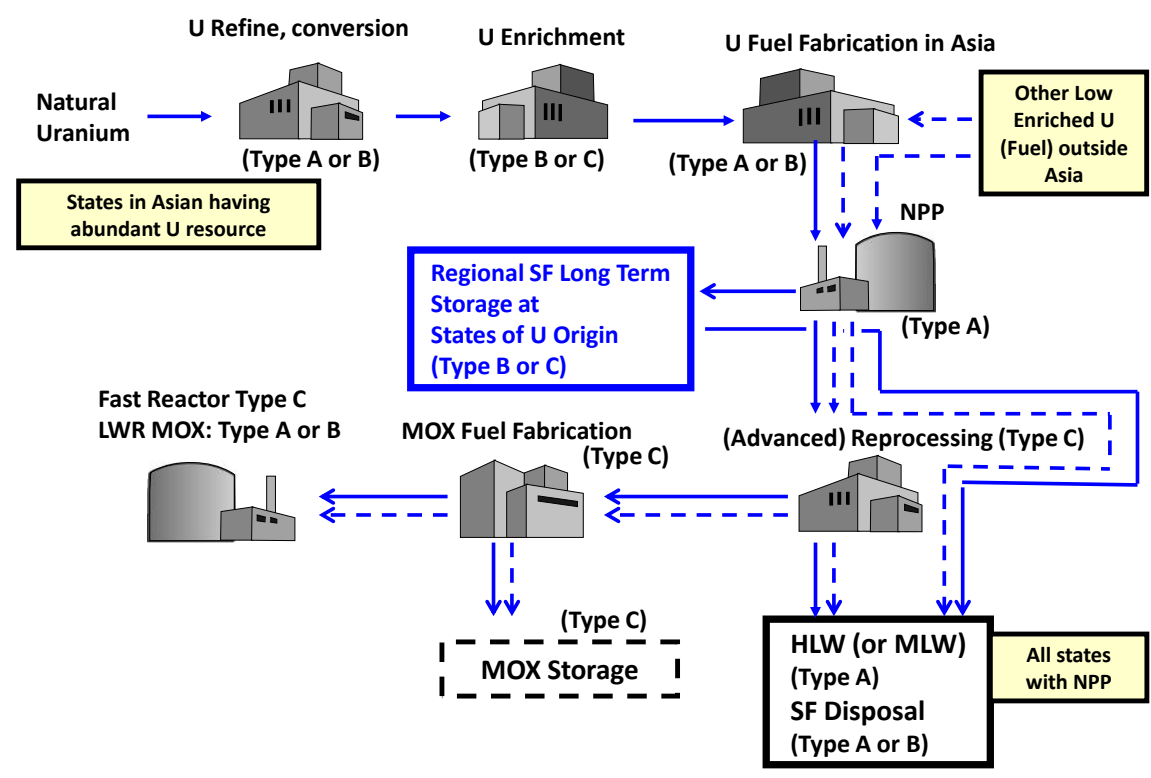

Figure 7. An Example of Potential MNA Cooperation in Asia Region

\section{Future perspective and challenges on MNA}

As discussed in Section 5, many prerequisites/features (Label a-l) have to be studied in order to establish a feasible and sustainable "Multilateral Approach Framework of Nuclear Fuel Cycle". Even if a proposal enables the fulfillment of all the prerequisites/features including equal right for peaceful use of nuclear energy, furthermore, remaining challenges may be how to make states have incentives toward or be attracted to the proposed MNA.

As shown in Section 2, EURATOM as a regional MNA was successfully established in the post-war. An incentive for European states to participate in EURATOM was to securely acquire source materials for nuclear energy development [2] due to the presence of the risk of shortage of energy source, although their Convention included safeguards systems to ensure that the nuclear materials to be used only for peaceful purpose.

The priorities for the above-shown example study are the following: "to eliminate inequality from the perspective of peaceful uses of nuclear power", "involvement of industry", "to have nuclear non-proliferation capacity of the current or higher level (including political 
and geopolitical perspectives)", "to realize international standards for safety and security", "to have higher economic potential for fuel cycle than a single state approach", "to eliminate conflicts/inconsistency with existing laws and regulations", and "to solve transport issues of nuclear fuel, etc". Particularly, involvement of industry would be a key issue when such incentive or attractiveness of the new proposal is discussed. Probably, nuclear societies including industry have internationally received greater recognition of the importance in Safety, Health and Radiation Protection; Physical Security; Environmental Protection and Handling of Spent Fuels and Wastes; Compensation for Nuclear Damage; Nuclear Non-Proliferation and Safeguards and Ethics, as described by Principle of Conduct [28], since the Fukushima Power Plant Accident.

Taking into account the example of EURATOM, the need of MNA for participants is the overriding issue in having "incentive" towards establishment of MNA. The author would like to note that the environment is getting ripe for the need of MNA, in terms of SF and waste treatment, maintenance and improvement in safety, security and nuclear non-proliferation-safeguards (3S).

There are still many challenges, pursuing incentives on economic efficiency, 3S, finding the solutions for nuclear material transportation within MNA, effective and efficient organizational management with not only member states but industries, and legal conflicts between new MNA's treaty/agreements and existing ones.

\section{Conclusion}

Even after Fu-NPP accident, use of nuclear reactors may be expanded particularly in emerging countries, where reliable systems of fresh fuel supply as well as proper management of spent fuels, free of any political disruptions to their nuclear reactors, are highly desirable. Establishment of international cooperative systems, which includes services for fresh fuel supply, spent fuel take-back/take-away, interim storage, reprocessing, and possibly repository disposal, may be able to contribute to a) enhancement of 3S, nuclear non-proliferation (Safeguards), Safety, and Security, b) economic rationality, c) promotion of confidencebuilding, and d) prevention to the occurrence of unfair business such as government-to-government transaction based on cradle-to-grave service that nuclear weapon state's privilege enables. This kind of internationally cooperative framework may become essential for future sustainable utilization of nuclear power.

\section{Acknowledgements}

The author should like to express sincere gratitude to Ms. M.Tazaki, Dr. M.Akiba, Dr. T.Adachi, Dr.T.Oda, Dr. R.Takashima, Dr. J-S.Choi, Professor A.Omoto and Professor S.Tanaka for their great contribution to this study. 
A part of this study is the result of "Study on establishment and sustainable management of multi-national nuclear fuel cycle framework" carried out under the Strategic Promotion Program for Basic Nuclear Research by the Ministry of Education, Culture, Sports, Science and Technology of Japan.

\section{Author details}

Yusuke Kuno

Department of Nuclear Engineering and Management,University of Tokyo, Japan

\section{References}

[1] U.S. Committee on the Internationalization of the Civilian Nuclear Fuel Cycle; Committee on International Security and Arms Control, Policy and Global Affairs; National Academy of Sciences and National Research Council http://www.nap.edu/ catalog/12477.html September 30, 2008

[2] Y.Kuno, J-S.Choi: Nuclear Eye 59-62, Vol.55, No.5, (2009) http://www.carnegieendowment.org/files/fuel_assurances_rauf.pdf

[3] http://www.carnegieendowment.org/files/fuel_assurances_rauf.pdf Individual Countries'Proposals at IAEA: INFCIRC/ 659(USA), INFCIRC/708(RUS), INFCIRC/ 707(UK), INFCIRC/704(GER), INFCIRC/683(JAP)

[4] Individual Countries' Proposals at IAEA: INFCIRC/ 659(USA), INFCIRC/708(RUS), INFCIRC/707(UK), INFCIRC/704(GER), INFCIRC/683(JAP)

[5] http://www.jaea.go.jp/04/np/activity/2008-07-10/2008-07-10-9.pdf

[6] Declaration on Atomic Bomb By President Truman and Prime Ministers Attlee and King, Washington", November 15, 1945

[7] Chester I. Barnard; Dr. J. R. Oppenheimer, Dr. Charles A. Thomas, Harry A. Winne, David E. Lilienthal, Chairman, "A Report on the International Control of Atomic Energy", Prepared for the Secretary of State's Committee on Atomic Energy by a Board of Consultants, Department of State Publication 2498, Washington, D.C., March 16, 1946, pp. 25-43

[8] The Baruch Plan, presented to the United Nations Atomic Energy Commission, June 14, 1946, atomicarchives.com, http://www.atomicarchive.com/Docs/Deterrence/ BaruchPlan.shtml

[9] Tariq Rauf, "Perspectives on Multilateral Approaches to the Nuclear Fuel Cycle", 30 April 2004, http://www.iaea.org/newscenter/focus/npt/npt2004_3004_mnfc_npt.pdf 
[10] Tariq Rauf; Fiona Simpson, “The Nuclear Fuel Cycle: Is it Time for a Multilateral Approach?", Arms Control Today, December 2004

[11] Yury Yudin, Multilateralization of the Nuclear Fuel Cycle: Assessing the Existing Proposals, UNIDIR/2009/4, United Nations Institute for Disarmament Research (UNIDIR), Geneva, Switzerland; p.6

[12] Costing of Spent Nuclear Fuel Storage", IAEA Nuclear Energy Series, No. NF-T-3.5, IAEA, Vienna, 2009, p42

[13] http://www.jaea.go.jp/04/np/activity/2008-07-10/2008-07-10-9.pdf \& U.S. and Russian Committees on Internationalization of the Nuclear Fuel Cycle, National Research Council and Russian Academy of Sciences: Internationalization of the Nuclear Fuel Cycle : Goals, Strategies, and Challenges, September 30, 2008,

[14] Y.Kuno, J-S.Choi: Internationalization and regional administration of nuclear fuel cycle - Why internationalize nuclear fuel cycle. Nuclear Eye 59-62, Vol.55, No.5 (2009)

[15] Tariq Rauf; Zoryana Vovchok, IAEA Bulletin 49-2, Vienna, March 2008, pp.62-63

[16] IAEA Board of Governors Conclude December Meeting", IAEA Top Stories \& Features, December 3, 2010, IAEA homepage, http://www.iaea.org/newscenter/news/ 2010/bog031210.html

[17] Russia Inaugurates World's First Low Enriched Uranium Reserve", IAEA Top Stories \& Features, December 17, 2010, IAEA homepage, http://www.iaea.org/newscenter/news/2010/leureserve.html

[18] INFCIRC/254/Rev.10/Part 1, IAEA, Vienna, 26 July 2011

[19] INFCIRC/640, IAEA, 22 February 2005, pp. 42-44

[20] M.Tazaki, Y.Kuno: “The Contribution of Multilateral Nuclear Approaches (MNAs) to the Sustainability of Nuclear Energy", Sustainability, ISSN 2071-1050, 4, 1755-1775 doi:10.3390/su4081755 (2012)

[21] Signed in 1995 and became effective in 1997. The member states are: Laos PDR, Myanmar, Malaysia, Brunei, Viet Nam, Thailand, Cambodia, Singapore, Indonesia, and the Philippines (10 ASEAN states)

[22] Y.Kuno, M.Tazaki, M.Akiba, T.Adachi, R.Takashima, A.Omoto, T.Oda, J-S.Choi, S.Tanaka: Study on Sustainable Regional Nuclear Fuel Cycle Framework from Nuclear Non-Proliferation Viewpoint - (I) Historical Review and Basic Concept to Propose New Framework, Institute of Nuclear Material Management (INMM) Annual Meeting, July 15-19, 2012, Orlando, USA (On-line Proceedings, 10 pages)

[23] Mitsunori Akiba, Takeo Adachi, Makiko Tazaki, Ryuta Takashima, Yusuke Kuno and Satoru Tanaka : Study on Sustainable Regional Nuclear Fuel Cycle Framework from Nuclear Non-Proliferation Viewpoint- (II) Prerequisites for formulation of the Framework, Institute of Nuclear Material Management (INMM) Annual Meeting, July 15-19, 2012, Orlando, USA (On-line Proceedings) 
[24] T.Adachi, M.Akiba, M.Tazaki, R.Takashima, A.Omoto, S. Hoshiba, Y.Kuno, S.Tanaka: Study on Sustainable Regional Nuclear Fuel Cycle Framework from Nuclear Non-Proliferation Viewpoint - (III) Proposal of Specific Agreements for Multilateral Nuclear Fuel Cycle Approach, Institute of Nuclear Material Management (INMM) Annual Meeting, July 15-19, 2012, Orlando, USA (On-line Proceedings)

[25] M.Tazaki, M.Akiba and Y.Kuno, "The Legal Aspects of Internationalization of Nuclear Fuel Cycle”, Paper No. 392033, Proc., GLOBAL 2011, Makuhari, Japan, Dec. 11-16, 2011

[26] J-S.Choi, Takuji Oda, S.Tanaka, and Y.Kuno, "The Roles of Industry for Internationalization of Nuclear Fuel Cycle", Paper No. 392343, Proc., GLOBAL 2011, Makuhari, Japan, Dec. 11-16, 2011

[27] http://carnegieendowment.org/publications/special/misc/nppe/ 